\title{
Erratum to: Improved initial vertex ordering for exact maximum clique search
}

\author{
Pablo San Segundo ${ }^{1}$ Alvaro Lopez ${ }^{1} \cdot$ Mikhail Batsyn $^{2} \cdot$ Alexey Nikolaev $^{2}$. \\ Panos M. Pardalos 2,3
}

Published online: 18 November 2016

(C) Springer Science+Business Media New York 2016

Erratum to: Appl Intell (2016) 45:868-880

DOI 10.1007/s10489-016-0796-9

The web page version of this article unfortunately contained a mistake. The author name Segundo, P.S. In Cite this article as: Segundo, P.S., Lopez, A., Batsyn, M. et al. Appl Intell (2016) 45: 868. doi:10.1007/s10489-016-0796-9 should read as San Segundo, P. The corrected line is shown below.

San Segundo P, Lopez A, Batsyn M et al (2016) Appl Intell 45:868. doi:10.1007/s10489-016-0796-9

The online versions of the original articles can be found at http://dx.doi.org/10.1007/s10489-016-0796-9.

Pablo San Segundo

pablo.sansegundo@upm.es

1 Centre for Automation and Robotics (UPM-CSIC), C/ Jose Gutiérrez Abascal, 2, 28006, Madrid, Spain

2 Laboratory of Algorithms and Technologies for Networks Analysis, National Research University Higher School of Economics, 136 Rodionova, Niznhy Novgorod, Russia

3 Center for Applied Optimization, University of Florida, 303 Weil Hall, Gainesville, FL 32611, USA 